\title{
Esterification of Solid Wood for Plastic Forming
}

\begin{abstract}
Mitsuru Abe, ${ }^{\mathrm{a}, *}$ Yukiko Enomoto, ${ }^{\mathrm{b}}$ Masako Seki, ${ }^{\mathrm{a}}$ and Tsunehisa Miki ${ }^{\mathrm{a}}$
Plastic formation from wood has recently attracted immense attention as a new method of producing three-dimensional materials by only one press. In this study, hydroxyl groups in (block-shaped) wood were replaced with ester groups to realize plastic formation. FT-IR measurements indicated that most of the hydroxyl groups in the block-shaped wood were replaced by ester groups after $4 \mathrm{~h}$ of treatment. The thermal properties of the esterified wood were investigated; the modulus of elasticity decreased remarkably when heated. Particularly, propionylated wood demonstrated a distinct softening point at relatively low temperatures, demonstrating its thermoplasticity. Additionally, the propionylated wood was stretched extensively by pressing with heat, showing its fluidity. Observation of the end grain of the esterified wood samples after pressing revealed that slippage occurred between the cells, resulting in the bulk flow of the wood. Finally, plastic formation using propionylated wood as the raw material was attempted, and a cup-shaped three-dimensional product was successfully formed. Contact angle measurements demonstrated that the cup-shaped molded product exhibited high water resistance. Thereafter, re-forming was attempted, using crushed fragments of the cup-shaped molded product, and a plate-shaped product was successfully re-formed. Thus, esterification is a promising method for increasing fluidity in solid wood, helping to enable its utilization in plastic forming.
\end{abstract}

Keywords: Wood; Flow Forming; Thermoplasticity; Esterification; Re-molding; Water resistance

Contact information: a: Multi-Materials Research Institute, National Institute of Advanced Industrial Science and Technology (AIST), 463-8560, Nagoya, Japan; b: Department of Biomaterial Sciences, Graduate School of Agricultural and Life Sciences, The University of Tokyo, 113-8657, Tokyo, Japan

*Corresponding author: m.abe@aist.go.jp

\section{INTRODUCTION}

Cutting, scraping, bending, and compression techniques are typically used in the fabrication of two-dimensional and/or three-dimensional materials from wood. Plastic formation from wood has recently attracted immense attention as a new method of producing three-dimensional materials. For example, wood-plastic composites (WPCs), produced by kneading wood flour and plastic, are being actively studied as raw materials in plastic formation (Clemons 2002; Chan et al. 2018; Mazzanti and Mollica 2019). However, to produce such WPCs, wood is used in its powder form. This powdering pretreatment is both time- and energy-consuming; further, unfortunately, the mechanically beneficial fiber structure of wood is lost during this pretreatment.

To overcome these shortcomings, a plastic formation method from wood has been developed. This method does not require the use of powdered wood or kneading of plastic and wood flour. In this method, a certain amount of water is flowed into the wood by heating and compression (Yamashita et al. 2006, 2009). In conventional wood compression, lumens of wood cells disappear, but the positional relation between the wood cells does not change. In the new method, however, the wood flow is caused by the sliding 
of each cell wall under certain conditions. Owing to the potential of substantial deformability, one-shot production of a complex molded body becomes possible. Recently, it was clarified that the fluidity of the wood, which is a measure of how easily the wood flows under low temperature and/or pressure, could be improved by impregnating the wood with a monomer, such as a phenol or melamine resin as a binder, rather than water (Miki et al. 2014a,b). Furthermore, by curing the resin monomer during heat treatment, water resistance was successfully imparted to the flow-formed product, and the dimensional stability was remarkably improved. However, because these resins are thermoset and cannot be re-formed, their recyclability remains a challenge. Therefore, a monomer of methyl methacrylate (MMA), a thermoplastic resin, was used as a binder to produce a composite material of wood and poly(methacrylic acid) (PMAA). As a result, thermoplastic flow-formed products that could be re-formed repeatedly were developed (Seki et al. 2014, 2016, 2017). However, as water cannot be used as a solvent in the impregnation solution because MMA is highly hydrophobic, it is necessary to employ an organic solvent, such as alcohol. Chemical modification of the wood surface can also be considered. By substituting the hydroxyl groups in the wood with the acetyl groups, the affinity between the wood and MMA is improved. Although these pretreatments demonstrated several effects, they are complicated and require further improvement. In addition to the above-described examples, using a thermoset, the resin composite-type flow forming of wood utilizes a large amount of petroleum-derived resins. Therefore, the development of another novel method is required.

Preparing a wood thermoplastic by derivatization appears to be one of the most promising solutions. Wood flour has been reported to exhibit thermal fusibility after esterification treatment (Funakoshi et al. 1979; Shiraishi et al. 1982; Matsuda and Ueda 1985; Hon and Xing 1992). An example of film-forming that utilized thermal fusibility and esterification was also reported (Shiraishi et al. 1982). Recently, several types of thermoplastic wood flour with ester substituents produced by efficient esterification processes of wood flour have been developed. Xie et al. (2007) reported an efficient esterification process for wood-based lignocellulosic materials in ionic liquids. They also reported that acetylated wood showed clear glass transition temperatures at $131.7^{\circ} \mathrm{C}$. Su et al. (2015) successfully obtained injection-molded wood-based plastics through a simple reaction of wood flour with phthalic anhydride in 1-methylimidazole at $15^{\circ} \mathrm{C}$ for $2 \mathrm{~h}$. Chen et al. (2017) developed highly translucent wood plastics by the esterification of ball-milled mulberry wood in a mixed solution of ionic liquid/dimethyl sulfoxide. Hassan et al. (2000a, b) succeeded in subjecting bagasse fibers to an esterification treatment with carboxylic anhydride and acetone to achieve thermal fusibility. Further, they stated that the use of fibrous biomass instead of wood flour affords the possibility of producing a novel material that utilizes the strength of fibers in plant biomasses. However, they only evaluated the meltability by observing the surface of the esterified bagasse after heat treatment with pressure and did not proceed to develop a three-dimensional flow forming of bagasse. Furthermore, for bulk wood, only some evaluations within the elastic range, such as the dimensional stability and dynamic viscoelasticity, have been performed (Nakano and Nakamura 1986a,b,c, 1987; Nakano 1988; Rowell 2013). Three-dimensional materials by flow forming have yet to be developed. In the flow phenomenon of bulk wood, it is necessary to soften the wood and induce a change in the mutual position of the cells owing to slippage between the cells. Therefore, an analysis of the plastic region is necessary. Additionally, after intercellular slippage occurred, the cells were required to recombine to maintain their shapes after the flow. 
In this study, the hydroxyl groups in block-shaped bulk woods were replaced with ester groups using a mixture of trifluoroacetic acid and carboxylic anhydride, and the physical, chemical, and thermal properties of the esterified woods were evaluated. Subsequently, a three-dimensional flow-formed product was developed. Furthermore, in addition to the assessment of the water resistance of the obtained product, its re-formation was also attempted to evaluate its recyclability.

\section{EXPERIMENTAL}

\section{Original Materials}

Pieces of Japanese cypress (Chamaecyparis obtusa, softwood) (Yamani, Co., Ltd., Nagano, Japan) and beech (Fagus crenata, hardwood) (Yamani, Co., Ltd., Nagano, Japan) with dimensions of $5.0 \mathrm{~mm}$ (longitudinal direction, $\mathrm{L}) \times 20 \mathrm{~mm}$ (radial direction, $\mathrm{R}) \times 20$ $\mathrm{mm}$ (tangential direction, $\mathrm{T}$ ) were used as wood specimens. They were cut from a larger stick with a transverse section of $20 \mathrm{~mm}(\mathrm{R}) \times 20 \mathrm{~mm}(\mathrm{~T})$. The initial mass of these specimens was $\sim 0.7 \mathrm{~g}$ for cypress and $\sim 1.2 \mathrm{~g}$ for beech. Trifluoroacetic acid, acetic anhydride, propionic anhydride, and methanol were purchased from FUJIFILM Wako Pure Chemical Corp. (Osaka, Japan) and utilized as obtained.

\section{Methods}

Esterification of wood

Trifluoroacetic acid and carboxylic anhydride were mixed at a ratio of 1 mol:1.1 mol, and the mixture was aged for $30 \mathrm{~min}$ and used as an esterification reagent. The esterification reagent $(30 \mathrm{~mL})$ was added to a one-neck reactor flask $(300 \mathrm{~mL}$, separate round-bottom flasks), and the specimen (dried wood) was placed into it. A stainless-steel net was placed over the wood to prevent the wood from floating in the solution. Thereafter, a reflux tube was set up to form a closed system. The degassing operation was performed at $-80 \mathrm{kPa}$, and the injection of nitrogen gas was repeated three times to remove residual air from the wood and replace the whole reaction system with nitrogen. The flask was immersed in an oil bath that was heated to $60{ }^{\circ} \mathrm{C}$, and the reaction solution was gently stirred for $1 \mathrm{~h}$ or $4 \mathrm{~h}$. Thereafter, the wood chips were collected, rinsed with $20 \mathrm{~mL}$ of methanol, and immersed in $300 \mathrm{~mL}$ of methanol to stop any further reaction. The methanol was replaced with unused methanol every $12 \mathrm{~h}$, and the operation was repeated three times to effectively wash the wood samples.

Table 1. Sample Codes and Differences among the Samples

\begin{tabular}{|c|c|c|c|}
\hline Sample Code & Wood species & Ester groups & Reaction time (h) \\
\hline Cy_Ac_1 & Cypress & Acetyl & 1 \\
\hline Cy_Ac_4 & Cypress & Acetyl & 4 \\
\hline Cy_Pr_1 & Cypress & Propionyl & 1 \\
\hline Cy_Pr_4 & Cypress & Propionyl & 4 \\
\hline Be_Ac_1 & Beech & Acetyl & 1 \\
\hline Be_Ac_4 & Beech & Acetyl & 4 \\
\hline Be_Pr_1 & Beech & Propionyl & 1 \\
\hline Be_Pr_4 & Beech & Propionyl & 4 \\
\hline
\end{tabular}


The obtained esterified wood was dried at $25{ }^{\circ} \mathrm{C}$ for $24 \mathrm{~h}$, after which it was dried at $105{ }^{\circ} \mathrm{C}$ for $24 \mathrm{~h}$. The samples are abbreviated as $\mathrm{Cy} \_\mathrm{Ac} \_1, \mathrm{Cy} \_\mathrm{Ac} \_4, \mathrm{Be} \_\mathrm{Ac} \_1$, Be_Ac_4, Cy_Pr_1, and Be_Pr_4, where the first codes, Cy and Be, refer to the types of wood (Cypress, $\mathrm{Cy}$; beech, Be); the next codes, Ac and Be, indicate the introduced ester groups (acetyl, Ac; propionyl, Pr), and the numbers represent the durations of the esterification reactions ( $1 \mathrm{~h}$ or $4 \mathrm{~h})$ (see Table 1$)$.

Before measurements were taken, the wood samples, which included unesterified woods, were abbreviated as $\mathrm{Cy}$ _untreated and Be_untreated, and then dried at $105{ }^{\circ} \mathrm{C}$ for $\geq 2 \mathrm{~h}$ and cooled to $25^{\circ} \mathrm{C}$ in a tight box with dried silica gels.

\section{Scanning electron microscopy}

Cross-sections of the wood samples were cut using a rotary microtome (RMS, Nihon Microtome Laboratory, Inc., Osaka, Japan). Then the inner structures of the wood samples were observed using a scanning electron microscope (JSM-IT500; JEOL Ltd., Tokyo, Japan) with an Au coating over the cut surface (Quick Coater VPS-020; ULVAC Ltd., Yokohama, Japan). The thicknesses of the cell walls of the woods were measured using ImageJ image analysis software (U.S. National Institutes of Health, ver. 1.8.0_112, Bethesda, MD, USA) with the SEM images at 1700-fold magnification. The thicknesses at 50 points were measured for each wood sample, and the average values were calculated.

\section{FT-IR measurement}

Fourier-transform infrared (FT-IR) measurements were performed on a Nicolet 6700 spectrometer (Thermo Scientific Inc., Waltham, MA, USA), and the standard attenuated total reflectance (ATR) method was employed. Flat pressed pieces obtained from the compression test described below were used as test pieces. The measurement was carried out at three or more points on the test piece, and it was observed that there were no noticeable differences in the results.

\section{Dynamic mechanical analysis}

A small test piece $(1 \mathrm{~mm} \times 1 \mathrm{~mm} \times 1 \mathrm{~mm})$ cut from the wood sample was subjected to DMA (TMA SS6100; Hitachi High-Tech Science Corp., Tokyo, Japan). An oscillating compressive load of $200 \pm 100 \mathrm{mN}$ (frequency of $0.03 \mathrm{~Hz}$ ) in the R direction was applied to the test piece, and dry nitrogen gas was purged during the measurement. The measurement was conducted with increasing temperature from $30{ }^{\circ} \mathrm{C}$ to $200{ }^{\circ} \mathrm{C}$ at a constant temperature ramping rate of $3{ }^{\circ} \mathrm{C} / \mathrm{min}$. The results of the heating process in the second cycle were computed.

\section{Compression test}

A small test piece $(5 \mathrm{~mm} \times 5 \mathrm{~mm} \times 5 \mathrm{~mm})$ cut from the wood sample was subjected to a compression test (Autograph AG-X plus $20 \mathrm{kN}$; Shimadzu Corp., Kyoto, Japan; load cell SFL-20KNAG; Shimadzu Corp., Kyoto, Japan). It was set on a press surface that was heated to $160{ }^{\circ} \mathrm{C}$ and pressed in the $\mathrm{R}$ direction at a speed of $1 \mathrm{~mm} / \mathrm{min}$. The press was stopped when the force on the specimen reached $10 \mathrm{kN}$. The apparent compressive stress was calculated based on the initial surface area of the specimen.

\section{Molding test}

Disk-shaped pieces of wood ( $\phi=35 \mathrm{~mm}$; thickness, $5 \mathrm{~mm}$; R direction) were subjected to a molding test. Press molding was performed using a metal mold for the cup- 
shaped product $(\phi=50 \mathrm{~mm})$ following the report of Yamashita et al. (2009). The temperature of the mold was raised to $160{ }^{\circ} \mathrm{C}$ by heating, and a release agent was applied inside the mold. Thereafter, a wood sample at $25{ }^{\circ} \mathrm{C}$ was placed into the mold and pressurized to $200 \mathrm{MPa}$ at a speed of $1 \mathrm{~mm} / \mathrm{s}$. After reaching $200 \mathrm{MPa}$, pressurization was allowed to proceed for $5 \mathrm{~min}$. Thereafter, the mold was air-cooled to $\leq 70{ }^{\circ} \mathrm{C}$, after which the molded sample was removed from the mold.

The molded sample was re-formed as follows: the cup-shaped product obtained by the above molding process was crushed into flakes ( $\phi$; approximately $2 \mathrm{~cm}$ ), which were then molded into a plate-like product $(50 \mathrm{~mm}$ (length) $\times 50 \mathrm{~mm}$ (width) $\times 10 \mathrm{~mm}$ (thickness)). The subsequent molding procedure was similar to the one used to obtain the cup-shaped product.

\section{Contact angle measurements}

The cup-shaped product was fixed in a horizontal position, and $2 \mu \mathrm{L}$ of pure water was dropped on the side surface at $25^{\circ} \mathrm{C}$. The contact angles were measured after $1 \mathrm{~s}$ and 20 s of deposition (PCA-11; Kyowa Interface Science Co., Ltd., Niiza, Japan).

\section{RESULTS AND DISCUSSION}

\section{Esterification of Wood}

Acetylation or propionylation of the wood samples was conducted. Figure 1 shows the changes in their appearances before and after esterification, and Table 2 shows the changes in weight.

\section{(a) Cy_untreated}

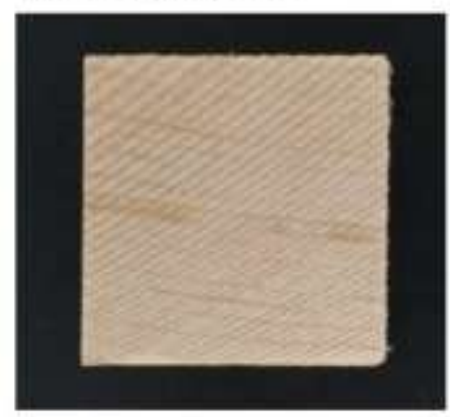

(d) Be_untreated

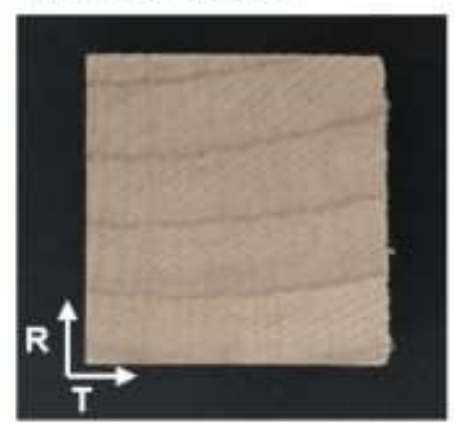

(b) Cy_Ac_4

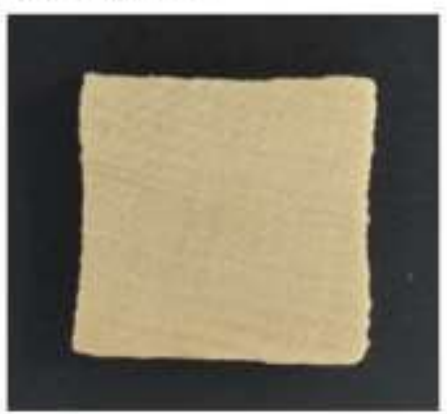

(e) Be_Ac_4

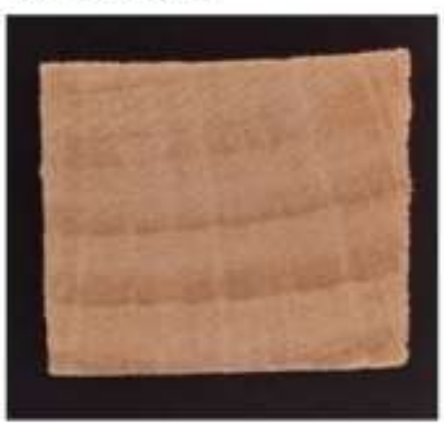

(c) Cy_Pr_4

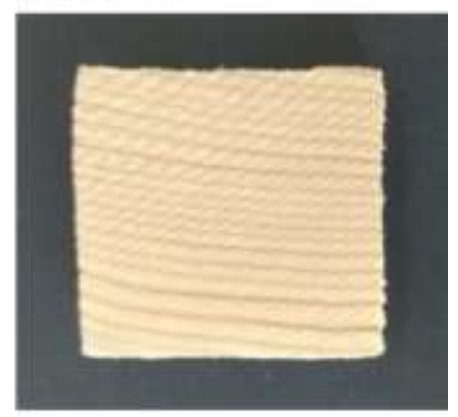

(f) Be_Pr_4

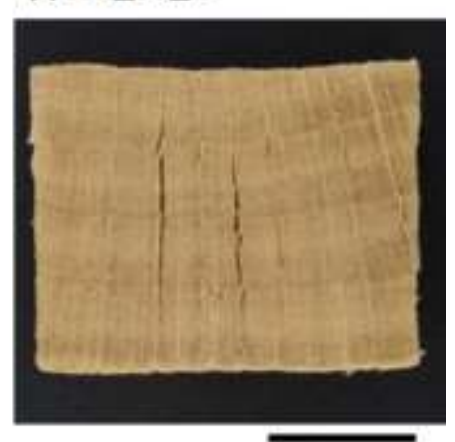

$1 \mathrm{~cm}$

Fig. 1. Photographs of the wood samples before and after esterification 
The cypress samples shrank slightly with esterification (Figs. 1a, 1b, and 1c), but beech tended to swell (Figs. 1d, 1e, and 1f). The samples were weighed, and the weight per gain (WPG) of both cypress and beech increased with increasing treatment time (Table 2).

Table 2. WPG of the Esterified Woods

\begin{tabular}{|c|c|}
\hline Sample & WPG (\%) \\
\hline Cy_Ac_1 & 28.1 \\
\hline Cy_Ac_4 & 41.1 \\
\hline Cy_Pr_1 & 36.9 \\
\hline Cy_Pr_4 & 54.8 \\
\hline Be_Ac_1 & 23.2 \\
\hline Be_Ac_4 & 34.8 \\
\hline Be_Pr_1 & 28.8 \\
\hline Be_Pr_4 & 47.4 \\
\hline
\end{tabular}

(a) Cy_untreated

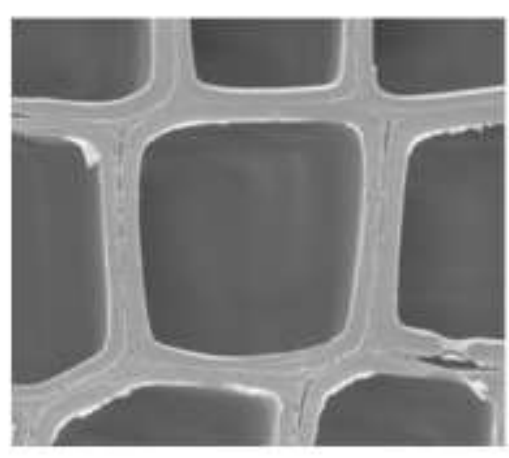

(c) Be_untreated

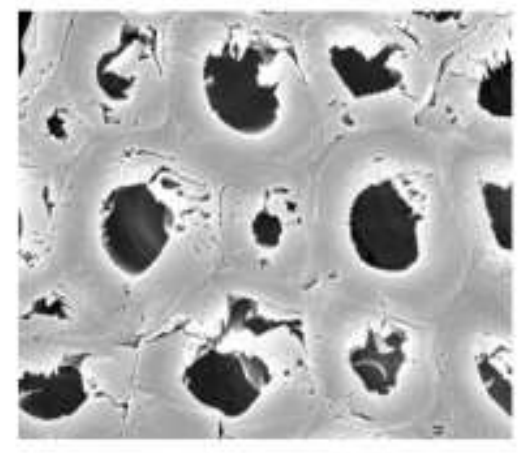

(b) Cy_Pr_4

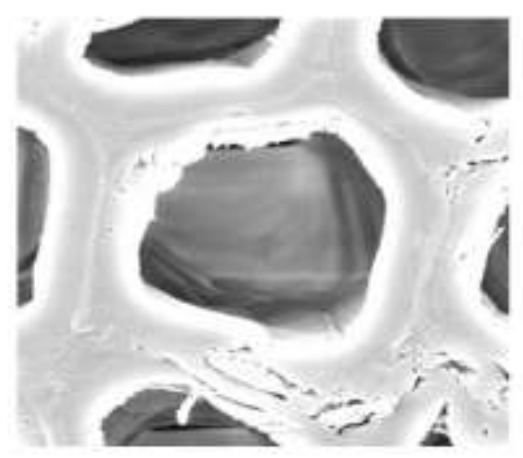

(d) Be_Pr_4

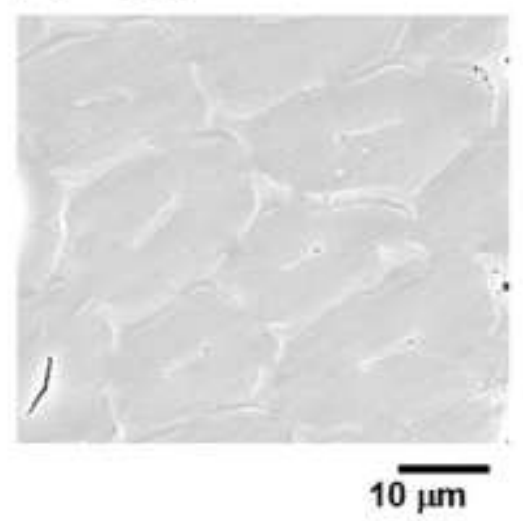

Fig. 2. Scanning electron microscopy images of untreated and $4 \mathrm{~h}$ propionylated woods

In both the cypress and beech samples, the propionylated woods exhibited larger WPG than the acetylated wood owing to the difference in the molecular weights of their substituents. When one was replaced with an acetyl group, the molecular weight increase was 42 , whereas it was 56 when the hydroxyl group was replaced by the propionyl group. Several differences were observed in the tree species. Cypress exhibited higher WPG than beech under any of the reaction conditions. This may have been caused by the differences in the composition of each of the woods. 
In the esterification of wood, it has been reported that the hydroxyl groups in lignin react more easily than those in cellulose (Rowell 1982; Rowell et al. 1994). Cypress, a kind of softwood, contains larger amounts of lignin than beech, which is a hardwood. Therefore, the esterification of cypress proceeded more easily than that of beech. It is also possible that the swelling of the cell wall reached its limit and was constrained in the case of beech, therefore, causing the WPG of beech to maintain a relatively low value.

SEM results of the esterified wood are shown in Fig. 2. Compared to the untreated cypress, Cy_untreated, Cy_pr exhibited an increased cell wall thickness (Fig. 2a and Fig. $2 \mathrm{~b})$. The average cell wall thickness of $\mathrm{Cy}_{-} \mathrm{Pr}_{-} 4$ was $4.60 \mu \mathrm{m}$, whereas that of Cy_untreated was $1.71 \mu \mathrm{m}$. In Cy_untreated, the rectangular cell walls were arranged in an orderly manner. In Cy_Pr, the distortion of the cell walls into pentagons, hexagons, or ellipses was observed.

Similar results were observed in both beech and cypress, and it was confirmed that the average wall thickness of the untreated beech, Be untreated, was $3.63 \mu \mathrm{m}$, but it swelled to $6.82 \mu \mathrm{m}$ owing to propionylation. Additionally, in Be_Pr_4, it was observed that the cell lumen diminished because of the swelling of the cell wall, and almost no voids were present. This disappearance of the cell lumen likely suppressed further swelling of the cell wall. This may have been one of the reasons why the WPG of beech remained lower than that of the cypress.

\section{FT-IR Measurements}

The esterified wood was subjected to FT-IR measurements to confirm the progress of the reaction (Fig. 3). To observe the interior of the esterified wood, ATR measurements were carried out using the pressed samples that were obtained in the compression test. In the data from the analysis (Fig. 3), sharp absorption bands appeared at $1226 \mathrm{~cm}^{-1}$ to 1236 $\mathrm{cm}^{-1}(v \mathrm{C}-\mathrm{O}$ and $\delta \mathrm{C}=\mathrm{O}), 1369 \mathrm{~cm}^{-1}(\delta \mathrm{C}-\mathrm{H})$, and $1730 \mathrm{~cm}^{-1}$ to $1737 \mathrm{~cm}^{-1}(\nu \mathrm{C}=\mathrm{O})$, and a set of these signals is characteristic of the ester group (Mohebby 2008). The absorption at $3500 \mathrm{~cm}^{-1}$ to $3300 \mathrm{~cm}^{-1}$ was ascribed to the $\mathrm{OH}$ stretching of water adsorbed by the wood cell wall (Pandey 1999; Mohebby 2008). The esterification of the wood remarkably reduced the intensity of this band, which indicated that the hydroxyl groups were replaced by the ester groups.

For the acetylation reaction, the peak intensity of the hydroxyl group decreased remarkably after $1 \mathrm{~h}$ of treatment (Cy_Ac_1 in Fig. 3a and Be_Ac_1 in Fig. 3c) and almost completely disappeared after $4 \mathrm{~h}$ of treatment (Cy_Ac_4 in Fig. 3a and Be_Ac_4 in Fig. $3 c)$.

For the propionylation treatment, the decrease in the peak intensity of the hydroxyl group was milder than that of the acetylation reaction, and a certain amount of the hydroxyl groups remained in the $1 \mathrm{~h}$-treated wood. However, the peak of the hydroxyl group of the propionylated wood, which was treated for $4 \mathrm{~h}$, was remarkably reduced, which suggested that most of the hydroxyl groups were replaced by the propionyl group. These results showed that the esterification proceeded sufficiently, owing to the hydroxyl groups present in the block-shaped wood piece. However, even with the use of the pressed test piece in this experiment, it may not have been possible to identify the hydroxyl groups contained in the highly crystallized cellulose. Therefore, the above results did not indicate that all the hydroxyl groups present in the wood were completely esterified. 
(a) Cy_Ac

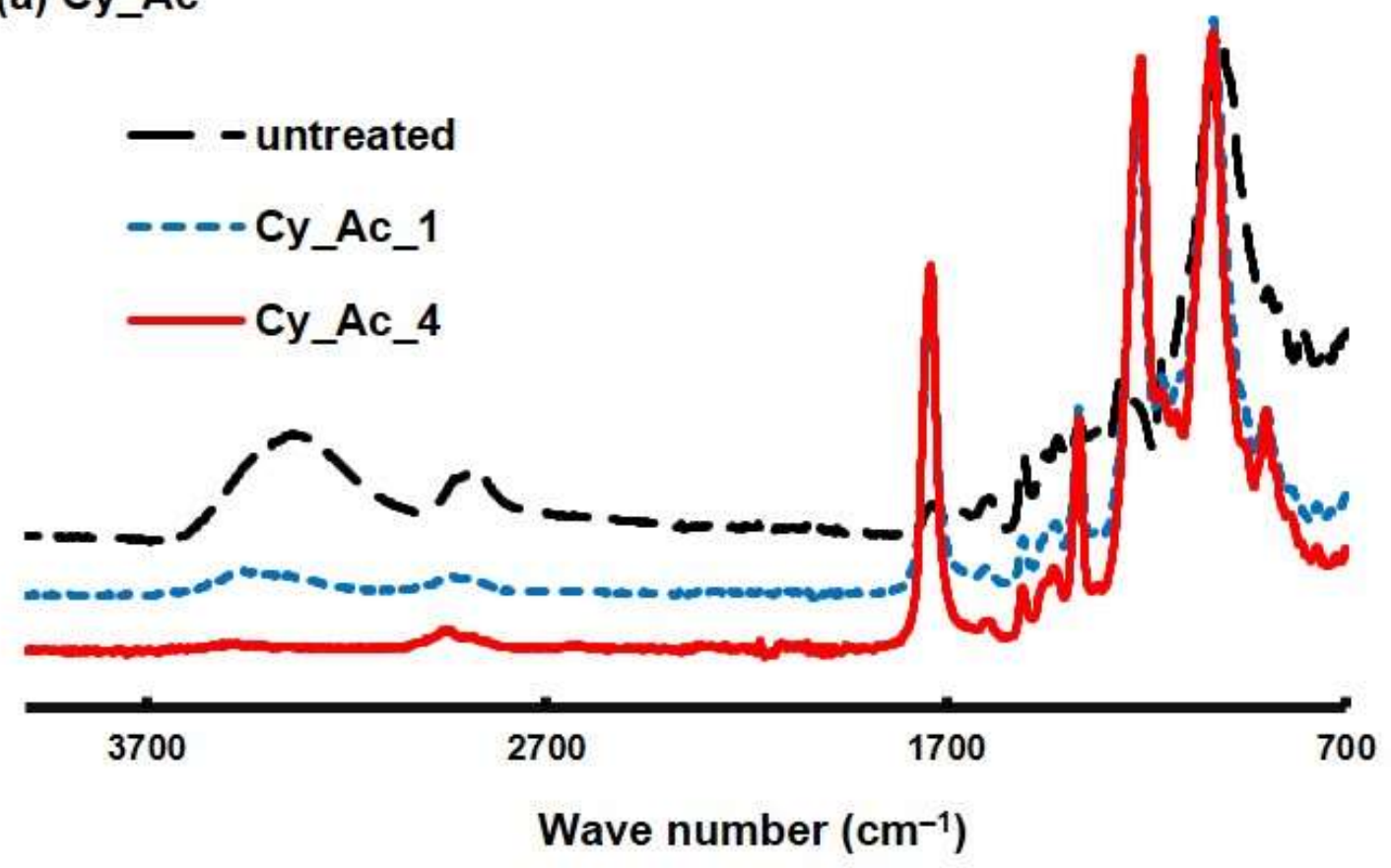

(b) Cy_Pr

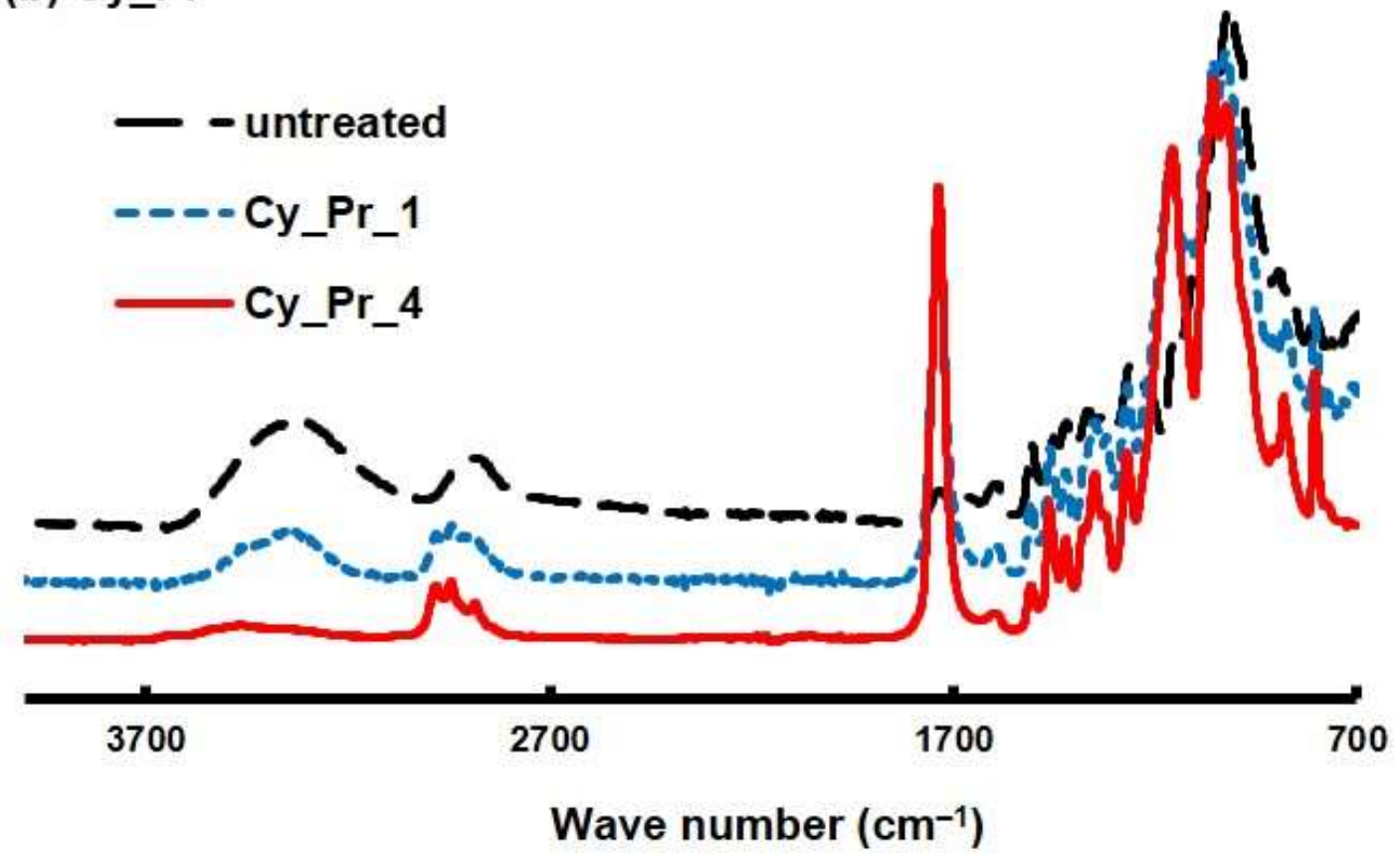


(c) Be_Ac

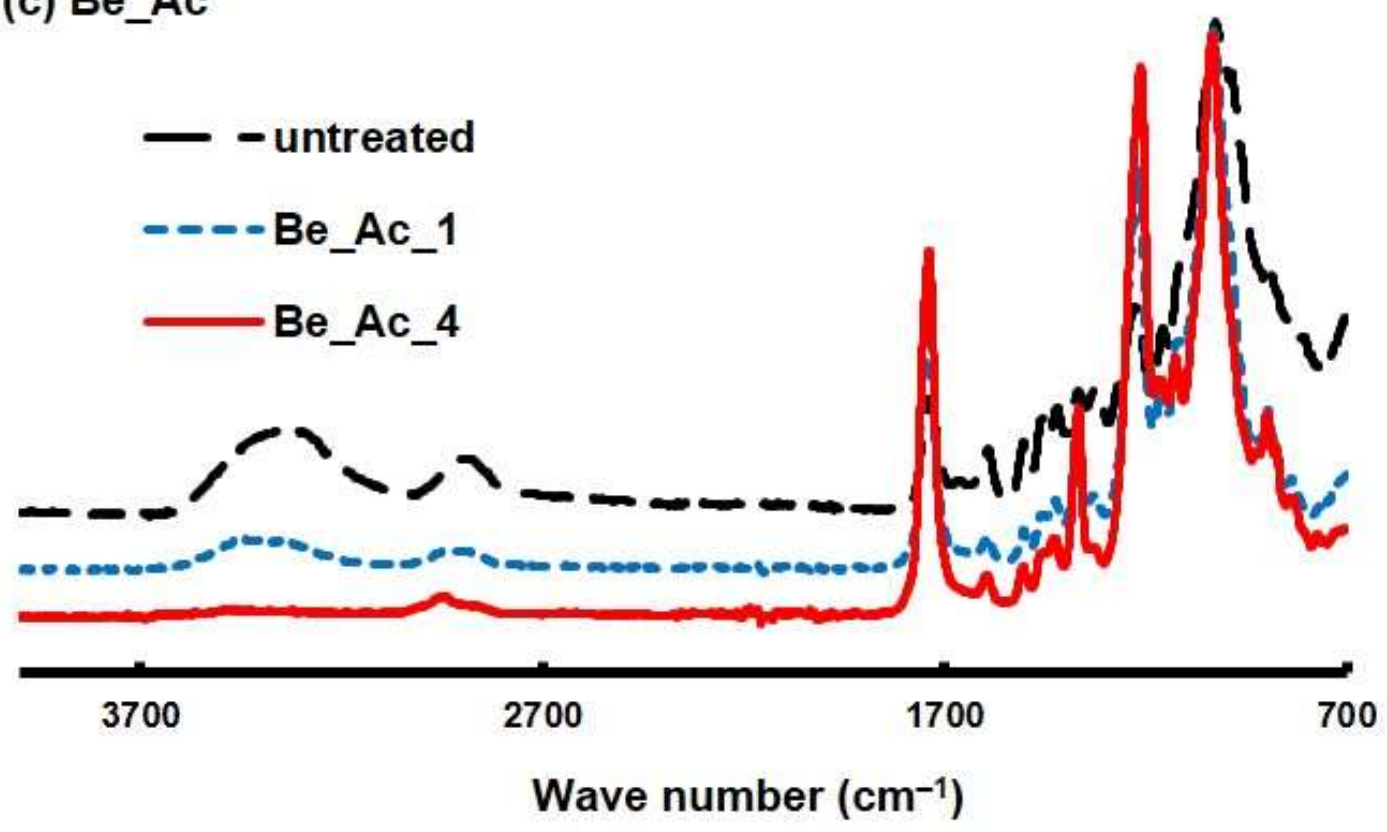

(d) Be_Pr

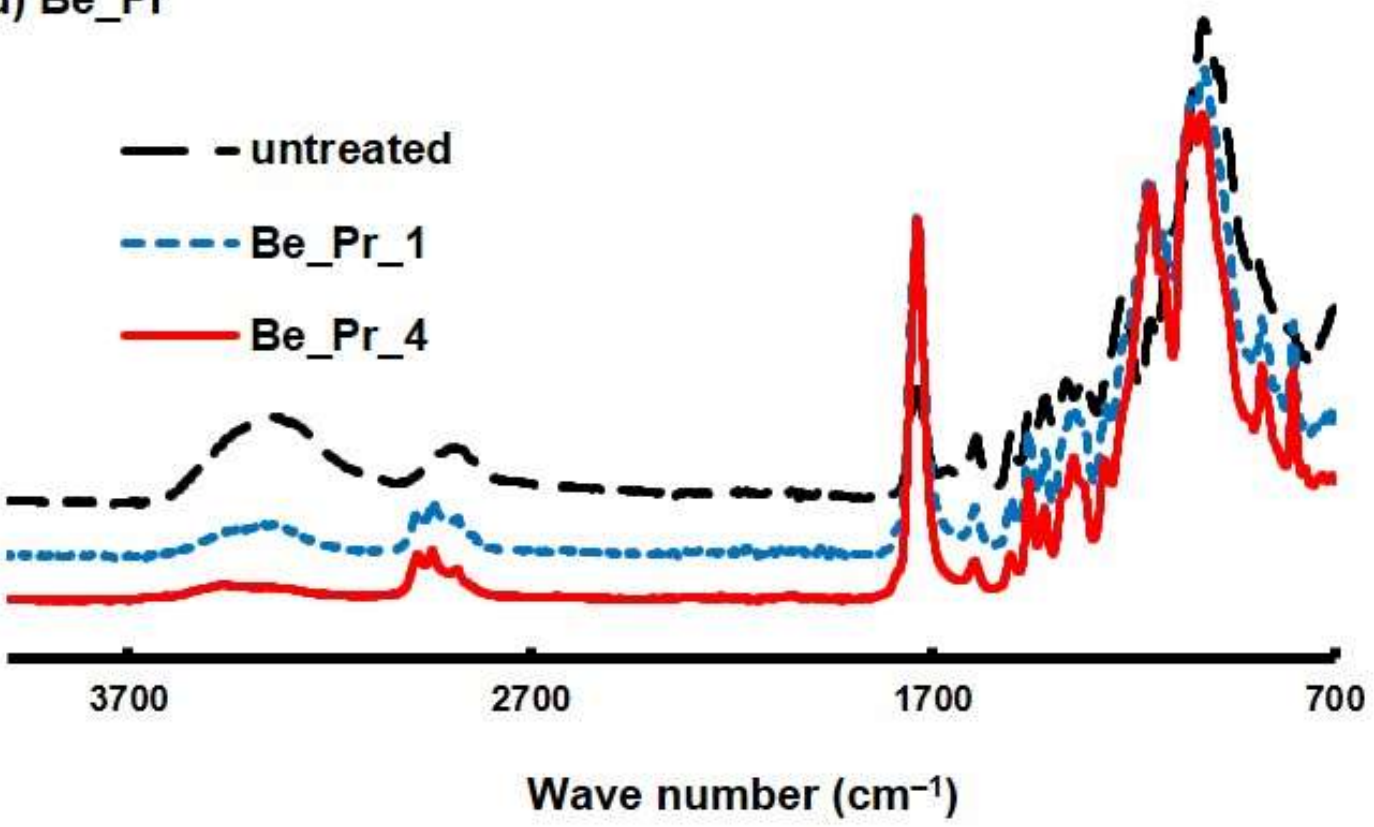

Fig. 3. Fourier transform infrared spectra of (a) Cy_Ac, (b) Cy_Pr, (c) Be_Ac, and (d) Be_Pr 


\section{Dynamic Mechanical Analysis}

The viscoelasticity of the esterified wood was characterized by DMA, and Fig. 4 shows the relative modulus of elasticity based on the elasticity at $50{ }^{\circ} \mathrm{C}$. Moreover, Cy_Ac exhibited a minor change in elasticity at $<150{ }^{\circ} \mathrm{C}$, but it decreased rapidly at $>160{ }^{\circ} \mathrm{C}$, and an inflection point was observed at approximately $190^{\circ} \mathrm{C}$. The softening point was defined as the intersection of the baseline and the tangent line of the inflection point, and its value was approximately $170{ }^{\circ} \mathrm{C}$ (Fig. 4a). For Cy_Pr, a sharp decrease in the elastic modulus was observed at approximately $110{ }^{\circ} \mathrm{C}$ (Fig. 4b). Further, a clear inflection point was observed at a lower temperature for $\mathrm{Cy}$ _Pr than for $\mathrm{Cy} \_\mathrm{Ac}$, and the softening point was detected at approximately $125{ }^{\circ} \mathrm{C}$. For beech, the tendency was almost similar to that of cypress. The elasticity of Be_Pr decreased at lower temperatures than that of Be_Ac. In Be_Ac, no inflection point was observed within the measurement range of this study (< $200{ }^{\circ} \mathrm{C}$ ). Therefore, the softening point could not be detected (Fig. 4c). However, in Be_Pr, an inflection point was observed. The detected softening point was at $150{ }^{\circ} \mathrm{C}$ for Be_Pr_1 and approximately $140{ }^{\circ} \mathrm{C}$ for Be_Pr_4.

These results confirmed that the wood was softened by the esterification treatment in each case (of cypress and beech), and the wood was imparted thermoplasticity. In particular, propionylation treatment exhibited a remarkable effect. Therefore, the propionylated wood samples were thoroughly examined in later sections.

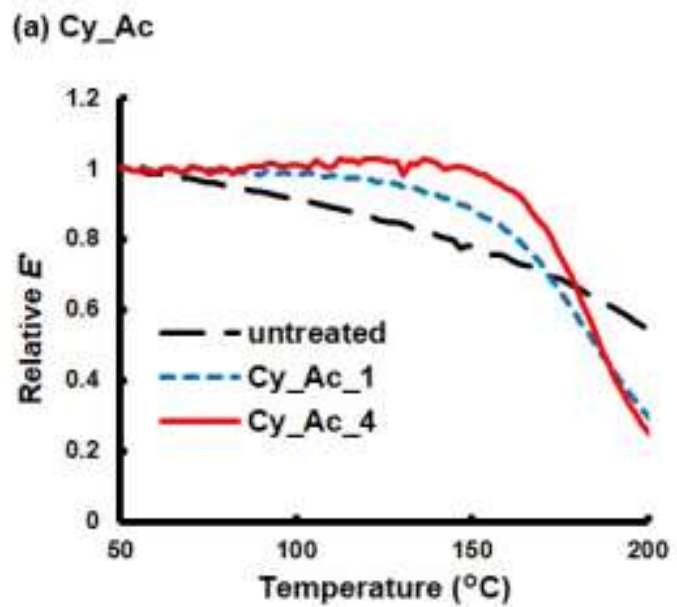

(c) Be_Ac

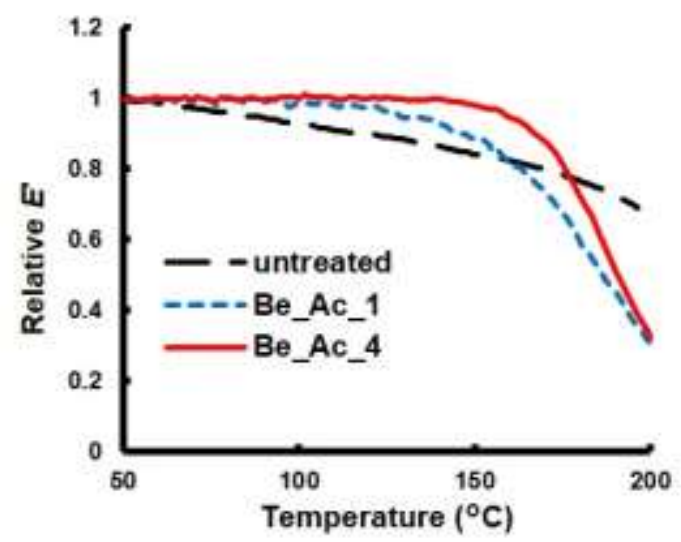

(b) $\mathrm{Cy}_{2} \mathrm{Pr}$

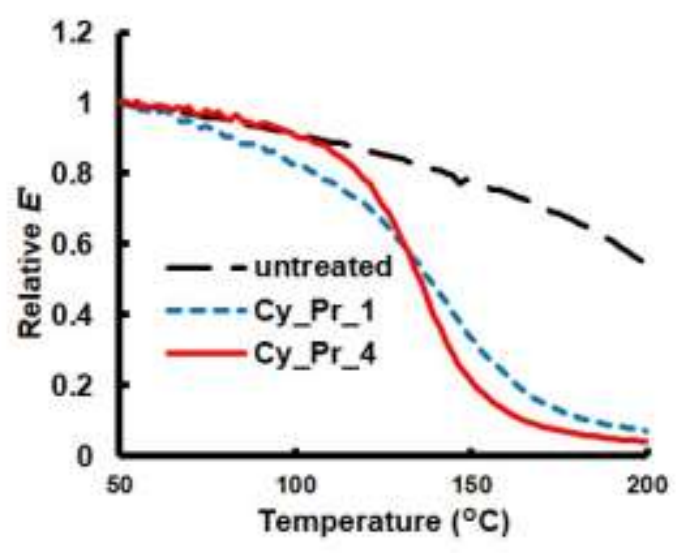

(d) Be_Pr

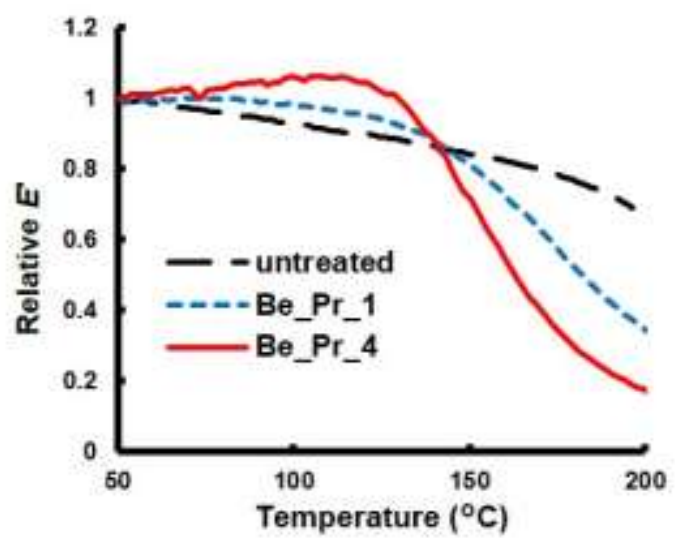

Fig. 4. Relative E' of (a) Cy_Ac, (b) Cy_Pr, (c) Be_Ac, and (d) Be_Pr based on $E^{\prime}$ at $50^{\circ} \mathrm{C}$. 


\section{Compression Test}

The propionylated woods were subjected to a compression test by heating to evaluate their fluidity. Based on the results of the viscoelasticity evaluation (Fig. $4 \mathrm{~b}$ and Fig. 4d), the mold temperature during compression was set at $160{ }^{\circ} \mathrm{C}$, and the fluidity (elongation), when compressed to $1 \mathrm{t}$ (approximately $400 \mathrm{MPa}$ ), was evaluated (Fig. 5).

(a) Cy_Pr

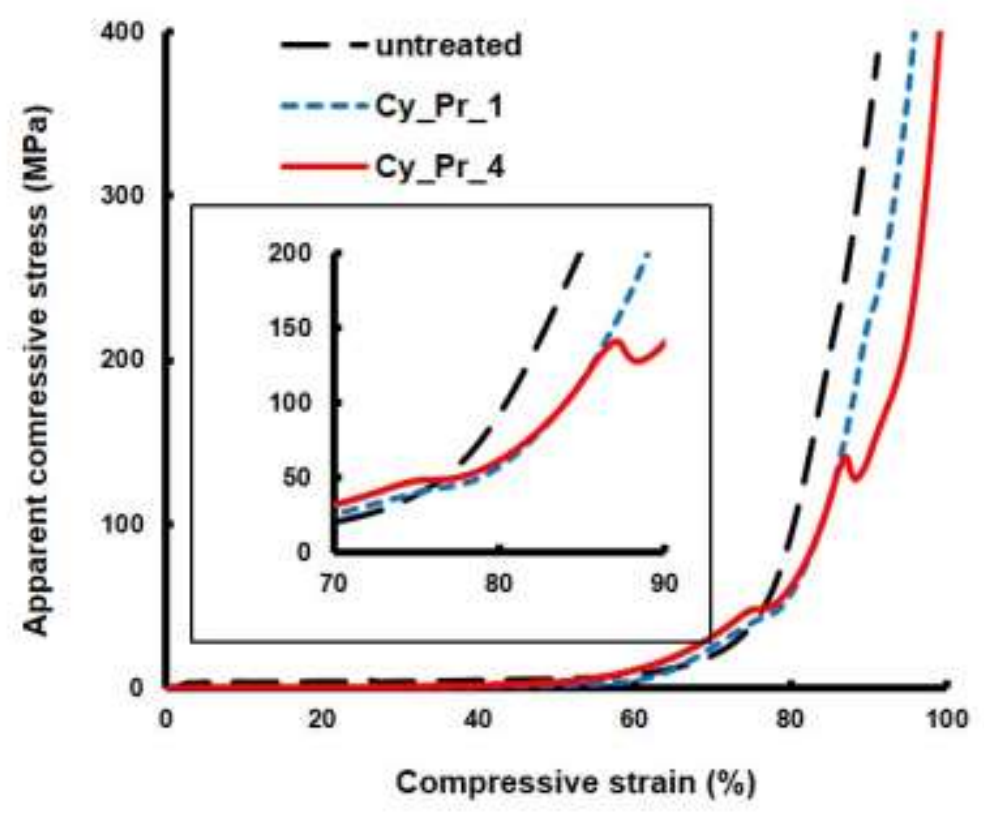

(b) Be_Pr

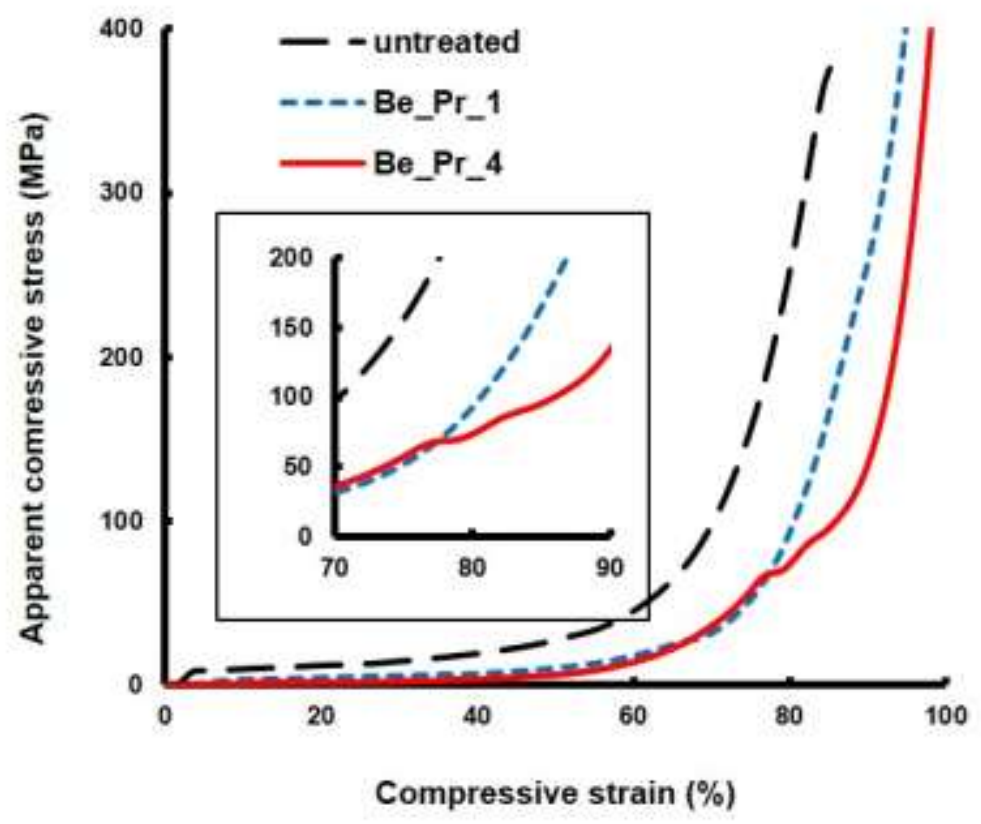

Fig. 5. Compressive stress-strain curves of (a) Cy_Pr and (b) Be_Pr 
At low pressure, the wood cell lumens were first crushed. Therefore, there was a region where the compression ratio increased with almost no corresponding increase in the load pressure. For $\mathrm{Cy}_{-}$untreated, the load pressure against the compressive strain increased exponentially in the region where the compressive strain exceeded approximately $60 \%$ (Fig. 5a, black). For Cy_Pr, there was a region where the slope of the stress-strain (S-S) curve decreased at a pressure of $30 \mathrm{MPa}$ to $50 \mathrm{MPa}$ (a compressive strain of approximately 75\%) (Fig. 5a, blue and red). For Cy_Pr_4 (Fig. 5a, red), which was subjected to prolonged propionylation, the compressive stress decreased remarkably around $140 \mathrm{MPa}$ (at a compressive strain of $85 \%$ ). These results indicate that the wood flowed under these pressure conditions.

Figure 6 shows results of the actual observation of the pressed sample. The sample pieces before pressing were $5 \times 5 \times 5 \mathrm{~mm}$ cubes, and their size is indicated by the dotted line in the image of the $\mathrm{Cy}$ _untreated sample. In Cy_untreated, a slight spreading was observed only in the T direction. Contrastingly, in Cy_Pr_1, it was observed that the wood pieces expanded greatly both in the T and L direction. In Cy_Pr_4, the tendency became even clearer, exhibiting significant expansion in both the $\mathrm{T}$ and $\mathrm{L}$ directions.

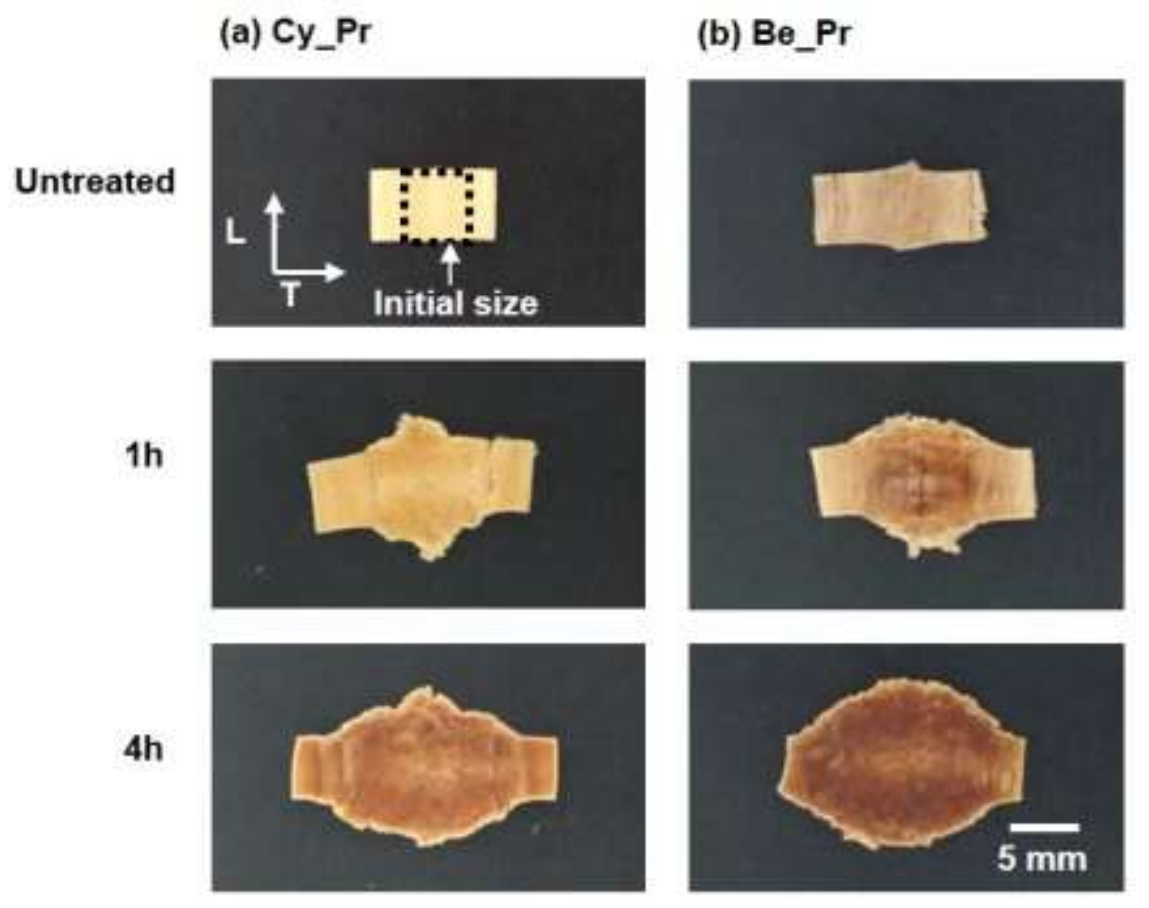

Fig. 6. Photographs of (a) Cy_Pr and (b) Be_Pr after compression testing

A micrograph of the end grain of compressed Cy_Pr_4 is shown in Fig. 7. For ordinary compressed wood, in which the wood did not flow, the medullary ray remained in a long and connected state. Conversely, in Cy_Pr_4 after the compression test, it was observed that the medullary ray was cut and scattered in pieces.

Additionally, the shape of each cell was complexly distorted when observed closely because the lumen had been crushed. However, the cell wall was not broken in most cells. These results indicate that $\mathrm{Cy}$ _Pr_4 was greatly stretched during heating and compression due to a change in the mutual positions of the wood cells. Although the ratio was reduced, cell wall breakage was confirmed in some cells, and cracks caused by continuous multiple 
cell wall breakages were also observed. The breakages in the cell wall may affect the fluidity of the bulk wood. To reveal the complete details of the trigger on the wood flow, many further systematic experiments and considerations are required. However, they are not within the scope of this study. The above results clarified that fluidity could be imparted on cypress via propionylation treatment.

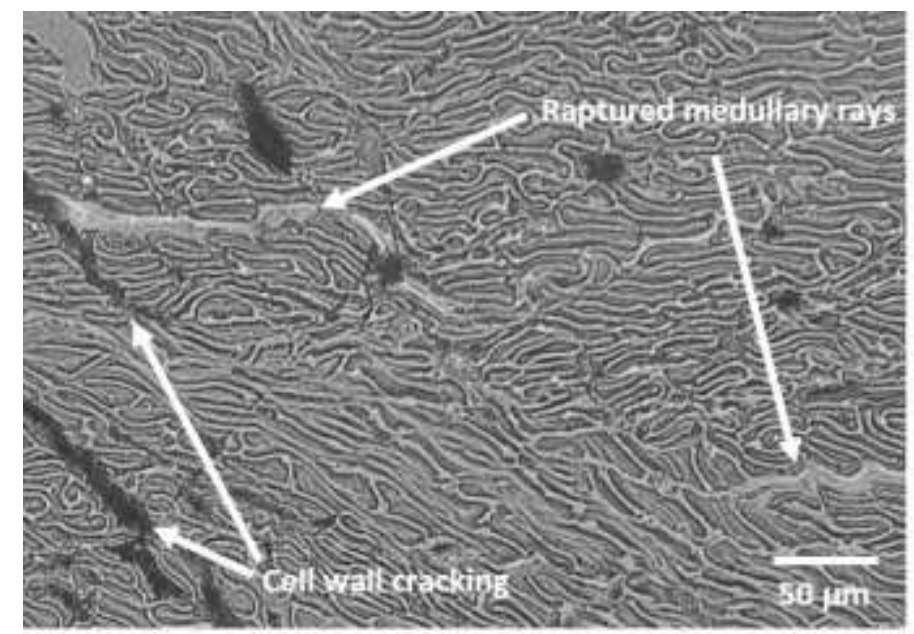

Fig. 7. Micrograph of Cy_Pr_4 after compression testing

For beech, the increase in the $\mathrm{S}-\mathrm{S}$ curve of the propionylated samples was relatively slow (Fig. 5b). As such, the samples tended to elongate greatly under relatively low load conditions of $\leq 30 \mathrm{MPa}$. For Be_Pr_4, a shoulder peak was observed at 70 to $100 \mathrm{MPa}$ (compressive strain of approximately 80\%). The appearance of the test piece after compression confirmed that the elongation of the wood samples during compression increased as the treatment time of the propionylation reaction increased (Fig. 6b). These results revealed that wood fluidity improved as propionylation progressed, regardless of the tree species.

\section{Plastic Forming Using Propionylated Wood}

First, dried Cy_untreated was used to produce a cup-shaped product. The photographs of $\mathrm{Cy}_{-}$untreated before and after compression are shown in Fig. 8a and Fig. 8 b, respectively. Cy_untreated did not flow at $160{ }^{\circ} \mathrm{C}$ with $200 \mathrm{MPa}$, and it did not form a single product. Next, a similar experiment was conducted using Cy_Pr_4, which exhibited a clear peak in the above-mentioned compression test (Fig. 5), as raw material. As a result, Cy_Pr_4 exhibited good fluidity, and a cup-shaped product was obtained (Fig. 8c). The obtained product possessed a smooth and shiny surface. These characteristics indicated that the raw material, Cy_Pr_4, flowed and firmly bonded to each other. These results show that the esterification treatment enabled the production of the three-dimensional product of wood by plastic forming without impregnation of resin.

Contact angle measurements were conducted on the side surface of the cup-shaped products to evaluate their water resistance. For the products obtained from $\mathrm{Cy}_{-}$untreated (Fig. 8b), the water droplet immediately permeated it, and the contact angle could not be measured. In contrast, for the cup-shaped product made by Cy_Pr (Fig. 8c), almost no water droplets permeated it, and the measured contact angle was $69.7^{\circ}$ (Fig. 9). After $20 \mathrm{~s}$ of dropping, the contact angle remained $>68^{\circ}$. These results revealed that the obtained cup-shaped product from Cy_Pr possessed excellent water resistance. 

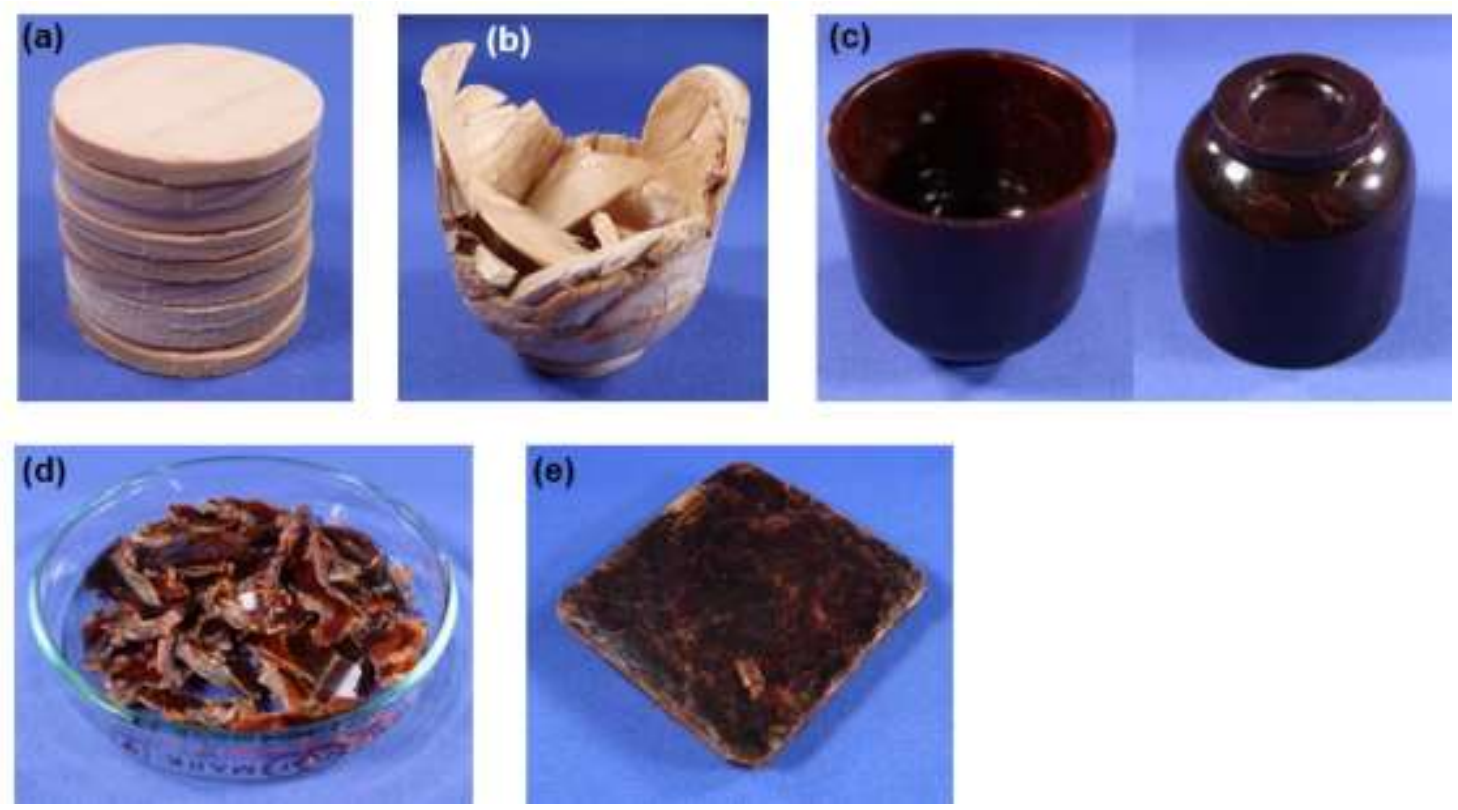

Fig. 8. Pictures of (a) original cypress, the three-dimensional molding products obtained from (b) Cy_untreated or (c) Cy_Pr, and (d) flaked three-dimensional molding product (c), and (e) remolded product

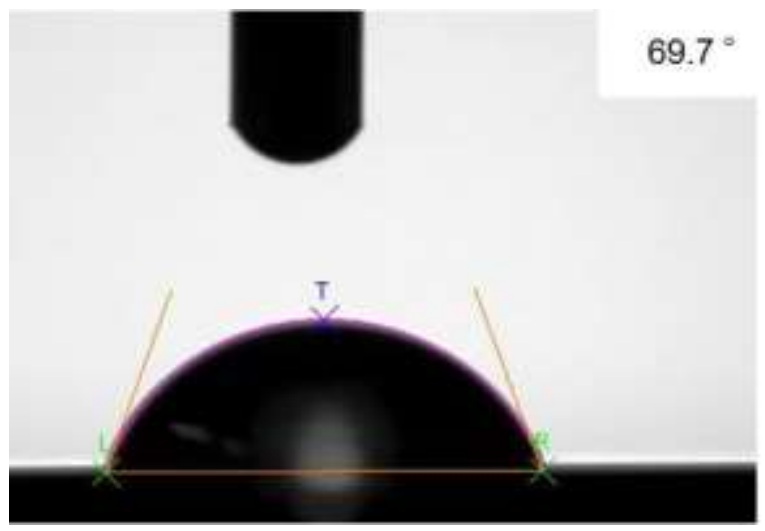

Fig. 9. Contact angle measurement of the three-dimensional molding product made of Cy_Pr

Next, the obtained product was re-formed by relying on the thermoplasticity of the propionylated wood. The obtained cup-shaped product was first crushed into flakes (Fig. $8 d)$. Subsequently, an attempt was made to re-form the flakes into a plate-like product under the same press and flow-forming conditions that formed the cup-shaped product. The obtained product is shown in Fig. 8e. The flakes flowed followed the shape of the mold and joined to form a single plate-like product. This result clarified that the re-formation of the flow-formed product was possible using propionylated wood as the raw material. However, compared to the cup-shaped product, the re-formed plate-like product possessed irregularities on the surface, which suggested that the flowability was poor. This finding calls for further investigation. The moisture content of the material or the strength of recombination generated after the first flow may have affected their fluidity. 


\section{CONCLUSIONS}

1. Block-shaped wood was esterified to achieve the plastic forming of the solid wood without impregnation of resin. In particular, propionylated wood exhibited great fluidity under the heating and pressure conditions. A cup-shaped three-dimensional product was successfully obtained.

2. Characterization of the esterified wood was conducted. It was observed that most of the hydroxyl groups in the bulk wood were replaced by the ester group after $4 \mathrm{~h}$ of esterification treatment. The cell walls of the solid wood were also swelled by the esterification treatment. The esterified wood, especially propionylated wood, exhibited thermoplasticity. Moreover, the propionylated wood stretched extensively when compressed under heat; i.e. it showed substantial fluidity. It was clarified that the slippage between the cells induced the bulk flow of the propionylated wood.

3. The obtained cup-shaped product exhibited high water resistance qualities.

4. Re-forming of the obtained cup-shaped product into a plate-like product was successfully attempted, hence verifying that the flow-formed product from esterified wood is recyclable.

\section{ACKNOWLEDGMENTS}

This work was financed by Grant-in-Aids (KAKENHI) for Young Scientist Research (A) (No. 16H06122 to TM) and for Young Scientist Research (B) (No. 19K15890 to MA) from the Japan Society for the Promotion of Science (JSPS).

\section{REFERENCES CITED}

Chan, C. M., Vandi, L.-J., Pratt, S., Halley, P., Richardson, D., Werker, A., and Laycock, B. (2018). "Composites of wood and biodegradable thermoplastics: A review," Polym. Rev. 58(3), 444-494. DOI: 10.1080/15583724.2017.1380039

Chen, J., Tang. C., Yue, Y., Qiao, W., Hong, J., Kitaoka, T., and Yang, Z. (2017). "Highly translucent all wood plastics via heterogeneous esterification in ionic liquid/dimethyl sulfoxide," Ind. Crop. Prod. 108, 286-294. DOI:

10.1016/j.indcrop.2017.06.054

Clemons, C. M. (2002). "Wood-plastic composites in the United States: The interfacing of two industries," Forest Products J. 52(6), 10-18.

Funakoshi, H., Shiraishi, N., Norimoto, M., Aoki, T., Hayashi, H., and Yokota, T. (1979). "Studies on the thermoplasticization of wood," Holzforschung 33(5), 159-166. DOI: 10.1515/hfsg.1979.33.5.159

Hassan, M. L., Rowell, R. M., Fadl, N. A., Yacoub, S. F., and Christainsen, A. W. (2000a). "Thermoplasticization of bagasse. I. Preparation and characterization of esterified bagasse fibers," J. Appl. Polym. Sci. 76(4), 561-574. DOI: 10.1002/(SICI)1097-4628(20000425)76:4<561::AID-APP14>3.0.CO;2-J

Hassan, M. L., Rowell, R. M., Fadl, N. A., Yacoub, S. F., and Christainsen, A. W. (2000b). "Thermoplasticization of bagasse. II. Dimensional stability and mechanical 
properties of esterified bagasse composite," J. Appl. Polym. Sci. 76(4), 575-586. DOI: 10.1002/(SICI)1097-4628(20000425)76:4<575::AID-APP15>3.0.CO;2-9

Hon, D. N.-S., and Xing, L. (1992). "Thermoplasticization of wood: Esterification," ACS Sym. Ser. 489, 118-132. DOI: 10.1021/bk-1992-0489.ch008

Matsuda, H., and Ueda, M. (1985). "Preparation and utilization of esterified woods bearing carboxyl groups. 4. Plasticization of esterified woods," Mokuzai Gakkaishi 31(3), 215-221. (In Japanese)

Mazzanti, V., and Mollica, F. (2019). "Rheological behavior of wood flour filled poly(lactic acid): Temperature and concentration dependence," Polym. Compos. 40, E169-E176. DOI: 10.1002/pc.24559

Miki, T., Seki, M., Shigematsu, I., and Kanayama, K. (2014a). "Preparation of three dimensional products using flow deformability of wood treated by small molecular resins," Adv. Mat. Res. 856, 79-86. DOI: 10.4028/www.scientific.net/amr.856.79

Miki, T., Seki, M., Tanaka, S., Sobue, N., Shigematsu, I., and Kanayama, K. (2014b). "Preparation of wood plastic composite sheets by lateral extrusion of solid woods using their fluidity," Procedia Engineer. 81, 580-585. DOI: 10.1016/j.proeng.2014.10.043

Mohebby, B. (2008). "Application of ATR infrared spectroscopy in wood acetylation," $J$. Agric. Sci. Technol. 10(3), 253-259.

Nakano, T., and Nakamura, H. (1986a). "Viscoelasticity of esterified wood specimens I. Stress relaxation behavior of caprated wood and the effect of ester content," Mokuzai Gakkaishi 32(3), 176-183. (In Japanese)

Nakano, T., and Nakamura, H. (1986b). "Viscoelasticity of esterified wood specimens II. The effect of the introduced acyl group on stress relaxation," Mokuzai Gakkaishi 32(5), 337-343. (In Japanese)

Nakano, T., and Nakamura, H. (1986c). "Viscoelasticity of esterified wood specimens III. The effect of ester content on dynamic mechanical properties," Mokuzai Gakkaishi 32(10), 820-826. (In Japanese)

Nakano, T., and Nakamura, H. (1987). "Viscoelasticity of esterified wood specimens IV. The effect of introduced acyl groups on dynamic mechanical," Mokuzai Gakkaishi 33(6), 472-477. (In Japanese)

Nakano, T. (1988). "Viscoelasticity of esterified wood specimens V. The effect of molar volume of introduced acyl groups," Mokuzai Gakkaishi 34(6), 516-521. (In Japanese)

Pandey, K. K. (1999). "A study of chemical structure of soft and hardwood and wood polymers by FTIR spectroscopy," J. Appl. Polym. Sci. 71(12), 1969-1975. DOI: 10.1002/(SICI)1097-4628(19990321)71:12<1969::AID-APP6>3.0.CO;2-D

Rowell, R. M. (1982). "Distribution of acetyl groups in Southern pine reacted with acetic-anhydride," Wood Sci. 15(2), 172-182.

Rowell, R. M. (2013). "Chemical modification of wood," in: Handbook of Wood Chemistry and Wood Composites, $2^{\text {nd }}$ Edition, CRC Press, Boca Raton, FL, USA, pp. 537-598.

Rowell, R. M., Simonson, R., Hess, S., Plackett, D. V., Cronshaw, D., and Dunningham, E. (1994). "Acetyl distribution in acetylated whole wood and reactivity of isolated wood cell-wall components to acetic-anhydride," Wood Fiber Sci. 26(1), 11-18.

Seki, M., Miki, T., Tanaka, S., Shigematsu, I., and Kanayama, K. (2014). "Effect of thermoplastic binder on flow deformation behavior of wood," Procedia Engineer. 81, 855-860. DOI: 10.1016/j.proeng.2014.10.088 
Seki, M., Tanaka, S., Miki, T., Shigematsu, I., and Kanayama, K. (2016). "Extrudability of solid wood by acetylation and in-situ polymerisation of methyl methacrylate," BioResources 11(2), 4025-4036. DOI: 10.15376/biores.11.2.4025-4036

Seki, M., Miki, T., Tanaka, S., Shigematsu, I., and Kanayama, K. (2017). "Repetitive flow forming of wood impregnated with thermoplastic binder," Int. J. Mater. Form. 10(3), 435-441. DOI: 10.1007/s12289-016-1291-x

Shiraishi, N., Aoki, T., Norimoto, M., and Okumura, M. (1982). "Thermoplasticization of cellulose and wood by graft-copolymerization and acylation," ACS Sym. Ser. 187, 321-348. DOI: 10.1021/bk-1982-0187.ch020

Su, M., Chen, J., Pan, Z., Li, X., Xu, A., and Hong, J. (2015). "Study on the preparation and mechanical properties of injection-moulded wood-based plastics," J. Appl. Polym. Sci. 132, 5, 41376. DOI: 10.1002/app.41376

Xie, H., King, A., Kilpelainen, I., Granstrom, M., and Argyropoulos, D. S. (2007). "Thorough chemical modification of wood-based lignocellulosic materials in ionic liquids," Biomacromolecules 8, 3740-3748. DOI: 10.1021/bm700679s

Yamashita, O., Yokochi, H., Imanishi, H., Miki, T., and Kanayama, K. (2006). "Flow phenomenon of bulk wood," T. Jpn. Soc. Mec. Eng. A 72(724), 2074-2078. (In Japanese) DOI: 10.1299/kikaia.72.2074

Yamashita, O., Yokochi, H., Miki, T., and Kanayama, K. (2009). "The pliability of wood and its application to molding," J. Mater. Process. Tech. 209(12-13), 5239-5244. DOI: $10.1016 / \mathrm{j} . j m a t p r o t e c .2008 .12 .011$

Article submitted: April 6, 2020; Peer review completed: May 9, 2020; Revised version received and accepted: June 26, 2020; Published: July 1, 2020.

DOI: 10.15376/biores. 15.3.6282-6298 